\title{
Sub-regional disparities in the use of antenatal care service in Mauritania: findings from nationally representative demographic and health surveys (2011- 2015)
}

Gebretsadik Shibre ${ }^{1}$, Betregiorgis Zegeye ${ }^{2}$, Bright Opoku Ahinkorah ${ }^{3}$, Dina Idriss-Wheeler ${ }^{4}$, Mpho Keetile $^{5}$ and Sanni Yaya ${ }^{6,7^{*}}$ (D)

\begin{abstract}
Background: Skilled antenatal care (ANC) has been identified as a proven intervention to reducing maternal deaths. Despite improvements in maternal health outcomes globally, some countries are signaling increased disparities in ANC services among disadvantaged sub-groups. Mauritania is one of sub-Saharan countries in Africa with a high maternal mortality ratio. Little is known about the inequalities in the country's antenatal care services. This study examined both the magnitude and change from 2011 to 2015 in socioeconomic and geographic-related disparities in the utilization of at least four antenatal care visits in Mauritania.

Methods: Using the World Health Organization's Health Equity Assessment Toolkit (HEAT) software, data from the 2011 and 2015 Mauritania Multiple Indicator Cluster Surveys (MICS) were analyzed. The inequality analysis consisted of disaggregated rates of antenatal care utilization using four equity stratifiers (economic status, education, residence, and region) and four summary measures (Difference, Population attributable risk, Ratio and Population attributable fraction). A 95\% Uncertainty Interval was constructed around point estimates to measure statistical significance.

Results: Substantial absolute and relative socioeconomic and geographic related disparities in attending four or more ANC visits (ANC4+ utilization) were observed favoring women who were richest/rich (PAR $=19.5,95 \%$ UI; 16.53, 22.43), educated (PAF $=7.395 \% \mathrm{UI} ; 3.34,11.26)$, urban residents $(D=19,95 \% \mathrm{UI} ; 14.50,23.51)$ and those living in regions such as Nouakchott $(R=2.1,95 \%$ UI; 1.59, 2.56). While education-related disparities decreased, wealthdriven and regional disparities remained constant over the 4 years of the study period. Urban-rural inequalities were constant except with the PAR measure, which showed an increasing pattern.
\end{abstract}

\footnotetext{
* Correspondence: sanni.yaya@uOttawa.ca

${ }^{6}$ School of International Development and Global Studies, Faculty of Social Sciences, University of Ottawa, 120 University Private, Ottawa, ON K1N 6N5, Canada

${ }^{7}$ The George Institute for Global Health, Imperial College London, London, UK

Full list of author information is available at the end of the article
}

C C The Author(s). 2021 Open Access This article is licensed under a Creative Commons Attribution 4.0 International License, which permits use, sharing, adaptation, distribution and reproduction in any medium or format, as long as you give appropriate credit to the original author(s) and the source, provide a link to the Creative Commons licence, and indicate if changes were made. The images or other third party material in this article are included in the article's Creative Commons licence, unless indicated otherwise in a credit line to the material. If material is not included in the article's Creative Commons licence and your intended use is not permitted by statutory regulation or exceeds the permitted use, you will need to obtain permission directly from the copyright holder. To view a copy of this licence, visit http://creativecommons.org/licenses/by/4.0/. The Creative Commons Public Domain Dedication waiver (http://creativecommons.org/publicdomain/zero/1.0/) applies to the data made available in this article, unless otherwise stated in a credit line to the data. 
Conclusion: A disproportionately lower ANC4+ utilization was observed among women who were poor, uneducated, living in rural areas and regions such as Guidimagha. As a result, policymakers need to design interventions that will enable disadvantaged subpopulations to benefit from ANC4+ utilization to meet the Sustainable Development Goal (SDG) of reducing the maternal mortality ratio (MMR) to 140/100, 000 live births by 2030.

Keywords: Antenatal care, Inequality, Mauritania, DHS, Global health

\section{Background}

Globally, more than 800 women still die each day from pregnancy and childbirth-related complications [1]. Although the global maternal mortality rate (MMR) decreased from 451, 000 to 295, 000 between 2000 and 2017 [2], more than two-thirds (68\%) of these deaths or nearly 200,000 maternal deaths took place in subSaharan Africa [2]. In 2017, an estimated 1100 women died during childbirth in Mauritania with a high MMR) (766 deaths per 100,000 live births) compared to subSaharan Africa (542 deaths per 100,000 live births) [2, 3].

Skilled antenatal care (ANC) is one of the vital services provided to pregnant women to enhance likelihood of safe pregnancy outcomes for the mother and fetus $[4,5]$. Pregnant women have the opportunity to use services such as nutrition, health checks, services that detect pregnancy risks, counselling and support services for women and their families, and skilled birth attendants which often lead to positive pregnancy outcomes or lower maternofetal deaths [6-8]. Numerous studies have shown the positive effect of ANC on the birth weight of a child [9-12], early detection of foetal abnormalities including the diagnosis of growth retardation $[13,14]$ and decrease in maternal and neonatal morbidity and deaths [15-17]. In addition, ANC coverage is a good measure for maternal health care service access and utilization during pregnancy [18-21].

Several studies in Africa have identified socioeconomic factors such as household wealth status, maternal education, subnational region, and place of residence as factors that influence ANC services [22-28]. Literature in Mauritania shows that maternal health services, including ANC, can be affected by factors such as maternal education, household economic status, place of residence, distance to facility, parity and previous adverse pregnancy outcomes $[29,30]$.

There is evidence of disparities within and across countries in maternal health services, particularly ANC four coverage (i.e., the percentage of women aged 15-49 with a live birth in a given time period that received ANC four or more times during their pregnancy) [3134]. Recent studies in low-and-middle-income countries show that ANC four coverage varied by at least 25 percentage points between the least and most educated as well as the poorest and richest women, while ANC one coverage varied by at least 10 percentage points between women in the richest and poorest subgroup in half of the countries [34]. We anticipate similar findings in Mauritania.

Available evidence in Mauritania highlighted disparities in maternal and child health services from a onetime survey completed in 2012 [29, 30]. In an effort to update the knowledge and investigate the change overtime, we used the recommended and rigorous inequalities techniques available through WHO's Health Equity Assessment Toolkit (HEAT) that houses ANC4 + data on Mauritania from 2011 and 2015 [35]. The HEAT toolkit helps to investigate inequalities in an indicator, such as ANC4+ utilization, using a wide range of inequality measures. This type of in-depth examination in inequality remains an important first step before running the traditional multivariable regression analysis. This study aimed to answer two main questions. First, what are the extent of socioeconomic, urban-rural and subnational disparities in ANC4 + in Mauritania? Second, what are the socioeconomic, urban-rural and sub-national disparity changes in ANC4+ utilization from 2011 to 2015?

\section{Method}

\section{Data source}

This study used data from the 2011 and 2015 Mauritania Multiple Indicator Cluster Survey (MICS). MICS started in the mid-90s by UNICEF to provide data on tracking progress toward the Millennium Development Goals (MDGs) and Sustainable Development Goals (SDGs), particularly those related to maternal-child health and education [36]. The Mauritania MICS 2011 is part of MICS4 that interviewed 12,754 women ages 15-49 from 10,116 households and gathered data on 9278 children under five [37]. The Mauritania MICS 2015 also forms part of MICS5 by which successful interviews were conducted among 14,342 women aged 15-49, 4691 men aged 15-49 from 11,765 households. Additionally, 10,663 questionnaires were administered to gather data on children under five [38]. The female questionnaire included different topics such as maternal health, maternal health care services such as antenatal care, and knowledge of HIV/AIDS. Finally, our sample included the 3569 and 4149 women, in 2011 and 2015 respectively, 
aged 15 to 49 years who received any ANC in 2 years preceding the surveys for their most recent birth.

\section{Selection of variables}

The outcome variable of interest in this study was ANC4+ utilization which uses data from the number of antenatal care visits made by a pregnant woman (i.e., count form 1, 2, 3 ... n) [39]. We defined ANC4+ utilization in this study as the percentage of women with a birth in the 2 years preceding the survey who received ANC four or more times during the pregnancy. Women who received the service from medical doctors, nurses, midwives are said to have received skilled ANC. Moreover, the questions about ANC were asked during the most recent live birth. The data used in this study were collected before the updated WHO new recommendation of at least eight ANC contacts, therefore, we used the original WHO benchmark of at least four antenatal care visits for ANC utilization by pregnant women in this study $[40,41]$.

\section{Equity stratifiers}

To measure inequality of ANC4+ utilization, we used the equality stratifiers of economic status, educational status (no education, primary and secondary/higher education), place of residence (rural, urban) and subnational region. As described in previous studies using DHS and MICS data, wealth index (classified as poorest, poor, middle, rich and richest) was calculated using Principal component Analysis (PCA) of household assets and other characteristics to approximate economic status [42]. There were 13 subnational regions in Mauritania, namely, Hodh charghy, Hodh Gharby, Assaba, Gorgol, Brakna, Trarza, Adrar, Dakhlett Nouadibou, Tagant, Guidimagha, Tirs-ezemour, Nouakchott Inchiri and Nouakchott.

\section{Inequality measures}

We measured the disparities of ANC4+ utilization using two steps. First, ANC4+ utilization was disaggregated using the above described equity stratifiers of economic status, education status, place of residence and subnational region. Second, we examined disparities in ANC4+ utilization using inequality measures of Difference, Population Attributable Risk (PAR), Population Attributable Fraction (PAF) and Ratio. While PAR and PAF are complex measures, Difference and Ratio are simple measures. Ratio and PAF measured relative inequalities, while Difference and PAR measured absolute inequalities.

Based on the recommendation of previous studies highlighting the use of relative and absolute as well as single and complex measures in a single study, our selection of summary measures was in compliance with and used all recommended measures [35, 43]. Using various types of summary measures may lead to differing conclusions; ignoring these findings can confuse or possibly negatively impact the decision-making process $[35,43]$. Unlike simple measures, complex measures are preferred because they account for the size of categories in a subpopulation, which is important for over-time analysis [35]. The advantages of simple measures are that they are easier to explain, interpret and understand by multiple stakeholders. Consequently, having simple and complex as well as relative and absolute measures in an inequality study provides a more accurate and realistic perspective to decision and policy making.

\section{Statistical analysis}

We used the 2019 WHO's HEAT software (version 3.1) to analyze the data [44]. The HEAT software technical notes [44] and the WHO handbook on health inequality monitoring [43] outline detailed calculations regarding inequality measures. In summary, Difference (D) and Ratio $(\mathrm{R})$ were calculated for each of the equity measures to render absolute and relative simple measures, respectively. If $\mathrm{D}$ rendered a value of zero $(0)$ or $\mathrm{R}$ a value of 1 , inequality did NOT exist [35, 43, 44]. For economic status, D was the richest group minus poorest group while $\mathrm{R}$ was the richest group divided by the poorest group. In education, the secondary/higher educated group minus uneducated group rendered $\mathrm{D}$ while $\mathrm{R}$ was the division of the former by the latter. We subtracted rural from urban for place of residence $\mathrm{D}$ and divided urban by rural for R. The difference for Subnational region included the region with highest ANC4+ utilization coverage minus region with lowest ANC4+ utilization, and Ratio (R) was calculated by dividing the two subgroups.

A value of zero (0) for PAR or PAF indicated inequality did NOT exist and the greater absolute value of both these complex measures indicated higher inequality. The PAR (the difference between the ANC4+ utilization estimate for the reference group and the national average) used the most disadvantaged subgroup as the reference group. For the ordered categorical dimensions, we used the richest subset for economic status, and the uneducated subset as the reference group for education, comparing it to the national average. Both the binary dimension of the place of residence (rural) and the nonordered categorical dimension of the subnational region with the highest estimate (Dakhlett Nouadibou for 2011 and Nouakchott for 2015) were used as the reference. To calculate PAF, we divided PAR by the national average $(\mu)$ and multiplied by $100[31,32]$.

We computed 95\% Uncertainty Intervals (UI) around point estimates of each measure for each survey year to: (i) examine whether ANC4+ utilization shows statistically significant disparities across the sub-groups of each 
equity stratifer, and (ii) determine whether or not the inequality changed over time. For inequality measures other than Ratio and PAF, the lower and upper bounds of the UI must not include zero to interpret that inequality exists. For Ratio and PAF, the interval should not include one. We assessed the changes of inequality for each summary measure by referring to the UIs for the different survey years; if the UIs did not overlap, inequality changed over time. The analysis took into account the complex nature of the MICS dataset including unequal probability of selection. For instance, the HEAT software applied "weighting" to rectify the problem of differing selection probability during the multi-stage selection of samples.

\section{Ethical consideration}

The WHO Health Equity Monitor database draws on Demographic and Health Survey (DHS) and the Multiple Indicator Cluster Survey (MICS) data from 95 countries [35]. Data analysis for this study is from publicly available MICS data set. Since the ethical clearance was approved by the institution that commissioned, funded and managed the overall UNICEF MICS program, further ethical approval was not required. Informed consent from the participants before the survey was obtained during the course of the survey. United Nations Children's Fund, National Office of Statistics (Mauritania) and relevant ethical review board of Mauritania were responsible to ensure and comply with appropriate ethical research protocols.

\section{Results}

Overall a total of 3569 and 4149 women in 2 years preceding the surveys participated in the 2011 and 2015 surveys, respectively. These women constituted those who had at least one live birth the 2 years preceding the survey. Of them, 4383 (56.8\%) were rural residents, and 1622 (21\%) were from the poorest (quintile) subgroups. More than one-fourth $(26 \%)$ and $2071(26.8 \%)$ of the respondents had no formal education and attended primary school, respectively.

Table 1 shows the socioeconomic, rural-urban and regional disparities in ANC4+ utilization across subpopulations in Mauritania from 2011 to 2015, with higher

Table 1 Percentage of women who used ANC4+ in 2011 and 2015 by socioeconomic and geographic characteristics

\begin{tabular}{|c|c|c|c|c|c|}
\hline \multirow{2}{*}{$\begin{array}{l}\text { Dimension of } \\
\text { Inequality }\end{array}$} & \multirow[t]{2}{*}{ Subgroup } & \multicolumn{2}{|l|}{2011} & \multicolumn{2}{|l|}{2015} \\
\hline & & Estimate (95\% UI) & women & Estimate (95\% UI) & women \\
\hline \multirow[t]{5}{*}{ Economic status } & Quintile 1 (poorest) & $34.68(30.39,39.24)$ & 748 & $47.22(41.87,52.65)$ & 874 \\
\hline & Quintile 2 & $39.93(36.11,43.87)$ & 728 & $53.32(48.50,58.08)$ & 870 \\
\hline & Quintile 3 & $51.95(47.58,56.29)$ & 694 & $63.22(59.00,67.25)$ & 824 \\
\hline & Quintile 4 & $53.57(49.41,57.69)$ & 754 & $71.79(68.04,75.25)$ & 833 \\
\hline & Quintile 5 (richest) & $63.91(58.93,68.61)$ & 644 & $82.43(77.85,86.24)$ & 746 \\
\hline \multirow[t]{3}{*}{ Education } & No education & $38.47(34.55,42.54)$ & 882 & $57.33(52.46,62.07)$ & 1131 \\
\hline & Primary school & $49.49(45.87,53.12)$ & 1256 & $54.29(49.32,59.18)$ & 815 \\
\hline & Secondary school + & $62.20(57.82,66.38)$ & 618 & $63.65(60.49,66.70)$ & 1463 \\
\hline \multirow[t]{2}{*}{ Place of residence } & Rural & $43.17(40.26,46.13)$ & 2101 & $54.40(50.86,57.89)$ & 2282 \\
\hline & Urban & $55.83(52.27,59.34)$ & 1468 & $73.41(70.47,76.15)$ & 1867 \\
\hline \multirow[t]{13}{*}{ Subnational region } & 01 Hodh charghy & $44.02(37.57,50.67)$ & 401 & $52.98(44.21,61.58)$ & 499 \\
\hline & 02 Hodh Gharby & $26.93(20.01,35.19)$ & 274 & $49.79(42.79,56.81)$ & 409 \\
\hline & 03 Assaba & $52.16(44.67,59.55)$ & 379 & $57.10(51.20,62.81)$ & 476 \\
\hline & 04 Gorgol & $41.19(34.88,47.80)$ & 335 & $58.25(50.59,65.53)$ & 505 \\
\hline & 05 Brakna & $49.71(41.24,58.20)$ & 322 & $68.59(62.07,74.45)$ & 425 \\
\hline & 06 Trarza & $63.44(57.77,68.76)$ & 350 & $72.38(65.47,78.36)$ & 297 \\
\hline & 07 Adrar & $29.51(23.11,36.83)$ & 79 & $48.34(34.17,62.78)$ & 19 \\
\hline & 08 Dakhlett Nouadibou & $64.38(57.68,70.57)$ & 107 & $73.59(65.71,80.21)$ & 135 \\
\hline & 09 Tagant & $27.14(20.23,35.36)$ & 98 & $49.27(41.39,57.20)$ & 22 \\
\hline & 10 Guidimagha & $33.50(26.68,41.08)$ & 254 & $38.68(30.26,47.82)$ & 326 \\
\hline & 11 Tirs-ezemour & $49.97(42.32,57.63)$ & 70 & $58.07(45.85,69.38)$ & 19 \\
\hline & 12 Nouakchott [12 Inchiri $\left.{ }^{\mathrm{a}}\right]$ & $57.83(52.45,63.03)$ & 895 & $70.49(54.57,82.61)$ & 5 \\
\hline & [13 Nouakchott $\left.{ }^{a}\right]$ & NA & NA & $80.34(76.14,83.95)$ & 1005 \\
\hline
\end{tabular}

\footnotetext{
${ }^{a}$ Rearranged regions for 2015 surveys. NA Not applicable for the 2011 survey. UI Uncertainty Interval
} 
coverage among the advantaged subgroups such as quintile 5 (richest), educated, urban residents and women from certain regions such as Nouakchott. ANC4+ utilization significantly varied across wealth quintiles with greater utilization among quintiles 5 and quintile 4 compared to quintiles 1 and 2 .

The coverage increased from 2011 to 2015 across all wealth quintiles. However, a higher increment among quintile 5 (18.5 percentage points [pp]) and quintile 4 (18.2 pp) were observed compared to quintiles 1 (12.5 pp) and 2 (13.4 pp).

The utilization of ANC was also higher among secondary school/higher subpopulations compared to uneducated and primary schools. ANC4+ utilization significantly increased among the uneducated (18.9\%) from 2011 to 2015, whereas among primary and secondary school subgroups, it increased by $4.8 \mathrm{pp}$. and $1.5 \mathrm{pp}$., respectively.

Similarly, a noticeable gap was seen between urban and rural settings in both survey years; higher ANC4+ utilization was observed among urban residents both in 2011 and 2015, and, the change between the subpopulation were dissimilar. Utilization increased by $17.6 \mathrm{pp}$. for urban residents and, to lesser extent, $11.2 \mathrm{pp}$. for rural residents over the 4 year period.

Similarly, ANC4+ utilization varied across regions from 2011 to 2015. In the Guidimagha region, the coverage increased only by $5.2 \mathrm{pp}$., whereas in the Brakna region, there was an $18.9 \mathrm{pp}$. increase (Table 1).

\section{Magnitude of inequality}

Table 2 shows significant socioeconomic, residence and subnational regional disparities in ANC4+ utilization in Mauritania from 2011 to 2015, favoring women with higher socioeconomic status, urban residents and regions such as Nouakchott. Significant absolute and relative wealth-driven disparities in ANC4+ utilization have been observed from 2011 to 2015 using simple (D, R) and complex (PAR, PAF) measures, favoring quintile 5 (richest) compared to quintile 1 (poorest) and quintile 2 (poorer).

Substantial disparities were observed across all the dimensions from 2011 to 2015. The Difference measure in 2011 (29.22, 95\% UI; 22.66, 35.78) and 2015 (35.20, 95\% UI; $28.39,42.02)$ indicate significant absolute economicrelated disparities favoring the advantaged subpopulation (richest). Similarly, the PAF measure in 2011 (32.09, 95\% UI; 25.71, 38.47) and 2015 (30.94, 95\% UI; 26.25, 35.63) show substantial relative economic-related disparities in ANC4+ utilization disfavoring the disadvantaged subpopulation (poorest) overtime.

The current study also shows substantial absolute and relative education-related disparities in ANC4+ both in 2011 and 2015 using all four measures (D, PAF, PAR, R)
Table 2 Socioeconomic and area-based disparities in ANC4+ utilization by the different inequality measures in Mauritania in 2011 and 2015

\begin{tabular}{llll}
\hline Dimension & & $\mathbf{2 0 1 1}$ & $\mathbf{2 0 1 5}$ \\
& Measure & Estimate $(\mathbf{9 5 \%}$ UI) & Estimate (95\% UI) \\
\hline Economic status & D & $29.22(22.66,35.78)$ & $35.20(28.39,42.02)$ \\
& PAF & $32.09(25.71,38.47)$ & $30.94(26.25,35.63)$ \\
& PAR & $15.53(12.44,18.61)$ & $19.48(16.53,22.43)$ \\
Education & R & $1.84(1.56,2.11)$ & $1.74(1.52,1.96)$ \\
& D & $23.72(17.87,29.58)$ & $6.31(0.60,12.03)$ \\
Residence & PAF & $27.41(21.89,32.94)$ & $7.30(3.34,11.26)$ \\
& PAR & $13.38(10.68,16.08)$ & $4.33(1.98,6.68)$ \\
& R & $1.61(1.41,1.81)$ & $1.11(1.00,1.21)$ \\
Region & PAF & $12.66(8.06,17.25)$ & $19.01(14.50,23.51)$ \\
& PAR & $7.45(6.07,8.83)$ & $10.45(9.10,11.80)$ \\
& R & $1.29(1.17,1.41)$ & $1.34(1.24,1.45)$ \\
& D & $37.45(27.46,47.43)$ & $41.66(32.00,51.31)$ \\
& PAF & $33.07(22.46,43.67)$ & $27.61(19.49,35.73)$ \\
& PAR & $16.00(10.87,21.13)$ & $17.38(12.27,22.49)$ \\
& R & $2.39(1.67,3.10)$ & $2.07(1.59,2.56)$ \\
\hline
\end{tabular}

$D$ Difference. $R$ Ratio. PAF Population Attributable Fraction. PAR Population Attributable Risk

favoring the advantaged subpopulation (secondary schools and higher) (Table 2). The pattern of education disparities decreased over the last 4 years in ANC4+ utilization. Although PAR dropped from 13.38 (95\% UI; $10.68,16.08)$ in 2011 to 4.33 (95\% UI; $1.98,6.68)$ in 2015, salient absolute education-related disparities in ANC4+ utilization existed favoring women who attended secondary school or higher compared to those who were uneducated. Similarly, the Ratio measure (1.61, 95\% UI; $1.41,1.81$ and 1.11, 95\% UI; 1.00, 1.21) in 2011 and 2015, respectively, indicated significant relative education-related disparities in ANC4+ utilization favoring subgroups with secondary or higher education.

Significant absolute and relative rural-urban inequality in ANC4+ utilization were observed in 2011 and 2015 using both simple (D, R) and complex (PAF, PAR) measures favoring women living in urban areas. PAR not only showed a significant difference between urban and rural; it also showed a significant increase between 2011 and 2015 from 7.45 (95\% UI; 6.07, 8.83) to 10.45 (95\% UI; 9.10, 11.80), also favoring urban regions. Measures of Difference, PAF and Ratio, revealed constant ruralurban disparity pattern in ANC4+ utilization in both years, but no significant change overtime from 2011 to 2015. For example, the PAF measure $(15.40,95 \%$ UI; 12.54, 18.26 and 16.60, 95\% UI; 14.46, 18.74) in 2011 and 2015 surveys, respectively, indicate substantial relative urban-rural disparities in ANC4+ utilization with 
higher service uptake among urban residents compared to their rural counterparts, but without over time change as the confidence intervals of the two-time period did overlap.

Substantial absolute and relative subnational regional inequality were observed both in 2011 and 2015 using simple (D, R) and complex (PAF, PAR) measures. The pattern of regional disparities was constant with no change over time from 2011 to 2015 survey points. For example, the Difference measure - 37.45 (95\% UI; 27.46, 47.43) in 2011 and 41.66 (95\% UI; 32.00, 51.31) in 2015 - demonstrated substantial absolute regional disparities in ANC4+ utilization favoring regions such as Dakhlett Nouadibou, but no change overtime. Similarly, the PAF measure (33.07, 95\% UI; 22.46, 43.67 and 27.61, 95\% UI; 19.49, 35.73) in 2011 and 2015 surveys, respectively, suggest significant relative regional inequality in ANC4+ utilization with no change over time (see Table 2 for more details).

\section{Discussion}

This study highlights the magnitude and change from 2011 to 2015 in socioeconomic and rural-urban inequalities as well as regional variations in antenatal care four service utilization. Substantial economic, education, urban-rural and regional disparities exist, favoring pregnant women who are from the richest quintile, educated, residing in urban settings and regions such as Nouakchott. We explored the disparities in ANC4+ utilization in Mauritania using HEAT, one of the most useful health equity assessments tools developed, recommended, and used internationally [43]. Evaluation of disparities regarding a health care indicator (i.e., ANC4+ utilization) using HEAT provides policymakers and researchers with valuable information on the prevailing status of that disparity within the country. The tool helps identify gaps among subgroups for interventions, policies, and programs regarding the indicator of interest across various dimensions of inequality (i.e., maternal education, transportation, health coverage), contributing to national priority-setting in health [35]. Furthermore, it allows investigation of the change of inequality overtime to create context specific strategies for areas where inequities have not changed to better serve the different segments of a population, particularly the most disadvantaged groups. Key measures (PAF and PAR) were selected due to their powerful ability to "show the potential for improvement in setting average that could be achieved if all the population subgroups had the same level of the indicator as the most advantaged (reference) group" [ [35], p.4].

Mauritania, categorized as a low-and-middle income country (LMIC), has unacceptably high maternal deaths $[2,3]$, therefore, antenatal care is a vital intervention to saving maternal and neonatal lives $[4,5]$. Evidence from other LMICS [45-49] highlighted the need for equity in maternal health services within a country and demonstrated that researching or working towards increasing the national coverage alone may aggravate within country disparities, overlooking those most in need, and stalling the movement towards achieving key maternal child health SDG targets [50]. Differences in socioeconomic status and geographic location disadvantage a significant number of pregnant women in LMICs who are not receiving ANC services, yet this is easily masked by national coverage numbers that show improvements overtime [45-49].

Consistent with previous studies [22, 24, 26, 28, 51], we noticed disproportionately higher ANC 4+ utilization among richest and rich women compared to poorest and poor women. In 2015, ANC4+ utilization among the richest women was higher by, on average, 35 percentage points compared to the poorest women. A possible reason for this disparity, as suggested by other studies, could be poverty - known to be a barrier to healthcare utilization in Sub-Saharan Africa (SSA) - because poor women are unable to afford the medical and non-medical costs associated with utilizing services such as ANC [52, 53]. This can limit the number of ANC visits, reduce early ANC initiation or prevent pregnant women from attending ANC entirely [26, 51]. Although some African countries offer free or subsidized maternal health services, pregnant women still have to pay for some direct medical costs (i.e., laboratory testing) and non-medical costs (i.e., transport to appointments) which become hindrances to using ANC services [54, 55].

Interestingly, a recent study by Ravit et al. (2020) looked at the impact of the obstetrical risk insurance (ORI) scheme on maternal healthcare utilization in Mauritania. ORI is a pre-payment scheme for pregnant women that is not based on risk pooling and regular payments, but rather focuses on an attempt to improve access to healthcare for pregnant women by lowering direct payments and increasing likelihood of using ANC (Ravit et al., 2020). Previous work had shown ORI availability at the district level had increased skilled ANC and delivery rates in health centres [56]. According to Ravit et al. (2020), the availability of ORI in the district levels is not enough; women need to be enrolled to improve use of health services during pregnancy. Barriers for not participating in ORI were aligned with some of the findings in this study that prevent many women from accessing ANC - access to ORI in their district, not deemed important/poor quality of health services, cost too high, distance/transportation and poor information [57].

Better ANC4+ utilization was found among women who attended secondary school and above, compared to women who had no formal education and attended 
primary school. This is similar to previous studies in SSA [22, 24, 28]. Studies have explained that education provides autonomy and empowers women with the capacity to make informed and responsible decisions about their health $[48,58]$. Educated women also have the advantage of a better understanding of health information given to them by health professionals regarding the importance of the continuum of maternal care [48]. In addition, educated women are also empowered to become more financially independent through employment and are thus able to afford the cost of ANC services [59].

Pro-urban disparities in service utilization of ANC4+ was evident in both survey years. Findings imply that if both absolute and relative urban-rural inequalities were avoided, the 2015 national ANC four utilization could potentially increase by approximately 10 percentage points and $17 \%$, respectively. Similar findings were observed in previous studies $[46,60,61]$. This could be due to better quality ANC services provided as well as the short distance to the healthcare facilities in urban regions $[46,49]$. In rural areas, there is limited distribution of health services, poor educational and employment status of residents as well as inadequate access to media, all of which are possible barriers to ANC utilization [45]. Compared to rural residents, studies have shown that urban residents generally have better knowledge regarding obstetric danger signs due to access to the media or health professionals, which increases their odds of attending ANC [62]. Similarly, in addition to associated costs, walking a long distance is a challenge for pregnant women and may discourage them from using ANC services [47]. This negative effect of long distance on the utilization of ANC and the continuum of maternal healthcare services has been documented in other studies $[47,49]$.

Another significant finding from the current study is the regional disparities in ANC uptake. ANC4+ utilization among women living in Nouakchott region were higher by 42 percentage points as compared to women living in the Guidimagha region. The finding also confirmed that the utilization among women in the Nouakchott region were 2 times higher than women residing in the Guidimagha region. Previous studies also confirmed regional variations in ANC coverage [63, 64]. Possible reasons could be differences in accessibility to ANC services, road and transportation access, affordable healthcare capacity, accessibility to health facilities, skilled health personnel and quality of care in the health care facilities $[65,66]$.

\section{Strength and limitations of the study}

The strength of this study is the use of WHO's HEAT to examine inequality in ANC4+ utilization using simple and complex as well as absolute and relative measures.
This approach provides various perspectives using different measures to assist policymakers in understanding the degree of disparity that exists among sub-groups, particularly outlining where a disproportionately higher or lower concentration of services exist. Additionally, there is comparability of findings across published papers using the same techniques, sources, and data through HEAT. However, the study has limitations. Methods did not include the analysis of explanatory factors for ANC utilization disparities. Future work could include studies that investigate factors that may explain the inequalities across different equity stratifiers.

\section{Conclusions}

The study examined not only the magnitude of disparities in ANC4+ utilization, but also assessed over time dynamics of disparities in Mauritania. As anticipated, and similar to findings in other regions of SSA, there was disproportionately lower service uptake of ANC4+ among women who were poor, uneducated, living in rural areas and regions such as Guidimagha. There is the need for policymakers to design interventions that will enable disadvantaged subpopulations to benefit from antenatal care services to meet the Sustainable Development Goals (SDG) so all countries should aim to reduce the maternal mortality ratio (MMR) to less than 140/ 100, 000 live births by 2030 [67]. Further studies are essential to investigate factors that lead to inequities in ANC utilization in emerging nations like Mauritania to make informed decisions that mitigate the existing or emerging issues using limited resources.

\section{Abbreviations}

ANC: Antenatal Care; D: Difference; MICS: Multiple Indicator Cluster Survey; EA: Enumeration Area; HEAT: Health Equity Assessment Toolkit; ICF: Inner City Fund; PAF: Population Attributable Fraction; PAR: Population Attributable Risk; PCA: Principal Component Analysis; R: Ratio; SDG: Sustainable Development Goal; UI: Uncertainty Interval; WHO: World Health Organization

\section{Acknowledgments \\ We acknowledge the Demographic and Health Surveys Program for making the DHS data available, and we thank the women who participated in the surveys. \\ Authors' contributions \\ SY, GS and BZ contributed to the conception and design of the study, interpreted the data, prepared the manuscript, and led the paper. BOA, DIW and MK helped with data analysis, provided technical support in interpretation of results and critically reviewed the manuscript for its intellectual content. SY had final responsibility to submit. All authors read and revised drafts of the paper and approved the final version.}

Funding

No funding was received for this work.

Availability of data and materials

The datasets generated and/or analyzed during the current study are available in

Health Equity Assessment Toolkit: Previous versions (who.int) 


\section{Declarations}

\section{Ethics approval and consent to participate}

Ethics approval was not required since the data is available to the public domain.

\section{Consent for publication}

Not applicable.

\section{Competing interests}

Bright Ahinkorah is on the Editorial Board of the journal.

\section{Author details}

'Department of Reproductive Health and Health Services Management, School of Public Health, Addis Ababa University, Addis Ababa, Ethiopia. ${ }^{2}$ HaSET Maternal and Child Health Research Program, Shewarobit Field Office, Shewarobit, Ethiopia. ${ }^{3}$ School of Public Health, Faculty of Health, University of Technology Sydney, Ultimo, Australia. ${ }^{4}$ Faculty of Health Sciences, University of Ottawa, Ottawa, Ontario, Canada. ${ }^{5}$ Population Studies and Demography, University of Botswana, Gaborone, Botswana. ${ }^{6}$ School of International Development and Global Studies, Faculty of Social Sciences, University of Ottawa, 120 University Private, Ottawa, ON K1N 6N5, Canada. ${ }^{7}$ The George Institute for Global Health, Imperial College London, London, UK.

Received: 10 December 2020 Accepted: 22 September 2021 Published online: 09 October 2021

\section{References}

1. Roser M, Ritchie H. Maternal mortality. Our World in Data; 2013.

2. UNICEF. Maternal Mortality. Available at https://data.unicef.org/topic/ma ternal-health/maternal-mortality/. Accessed 29 Apr 2020.

3. Knoema World Data Atlas. Mauritania Maternal deaths, 1960-2020 - knoema. com [Internet]. 2017 [cited 2021 Aug 4]. Available from: https://knoema. com//atlas/Mauritania/topics/Health/Health-Status/Maternal-deaths.

4. $\mathrm{WHO}$. WHO recommendations on antenatal care for a positive pregnancy experience. 2016. p. 152. ISBN 9789241549912.

5. Vogel JP, Habib NA, Souza JP, Gu Imezoglu AM, Dowswell T, Carroli G, et al. Antenatal care packages with reduced visits and perinatal mortality: a secondary analysis of the WHO Antenatal Care Trial. Reprod Health. 2013;10: 19. https://doi.org/10.1186/1742-4755-10-19.

6. Mbuagbaw L, Medley N, Darzi AJ, Richardson M, Habiba Garga K, OngoloZogo P. Health system and community level interventions for improving antenatal care coverage and health outcomes. Cochrane Database Syst Rev. 2015;12:CD010994. https://doi.org/10.1002/14651858.CD010994.

7. Anastasi E, Borchert M, Campbell OMR, Sondorp E, Kaducu F, Hill O, et al. Losing women along the path to safe motherhood: why is there such a gap between women's use of antenatal care and skilled birth attendance? A mixed methods study in northern Uganda. BMC Pregnancy Childbirth. 2015;15:287. https://doi.org/10.1186/s12884-015-0695-9.

8. Tadele N, Lamaro T. Utilization of institutional delivery service and associated factors in Bench Maji zone, Southwest Ethiopia: community based, cross sectional study. BMC Health Serv Res. 2017;17:101. https://doi. org/10.1186/s12913-017-2057-y.

9. Habibov NN, Fan L. Does prenatal healthcare improve child birthweight outcomes in Azerbaijan? Results of the national demographic and health survey. Econ Human Biol. 2011;9(1):56-65. https://doi.org/10.1016/j.ehb.2010. 08.003.

10. Wehby GL, Murray JC, Castilla EE, Lopez-Camelo JS, Ohsfeldt RL. Prenatal care demand and its effects on birth outcomes by birth defect status in Argentina. EconHuman Biology. 2009;7(1):84-95. https://doi.org/10.1016/j. ehb.2008.10.001

11. Evans WN, Lien DS. The benefits of prenatal care: evidence from the PAT bus strike. J Econ. 2005;125(1):207-39. https://doi.org/10.1016/j.jeconom.2 004.04.007.

12. Rosenzweig MR, Schultz TP. Estimating a household production function: heterogeneity, the demand for health inputs, and their effects on birth weight. J Polit Econ. 1983;91(5):723-46. https://doi.org/10.1086/261179.

13. Backe B, Consultant JN. Effectiveness of antenatal care: a population based study. BJOG Int J Obstet Gynaecol. 1993;100(8):727-32. https://doi.org/1 0.1111/j.1471-0528.1993.tb14263.x.
14. Every Woman Every Child. The global strategy for women's, children's and adolescents' health (2016-2030): survive, thrive, transform. Geneva: Every Woman Every Child; 2015.

15. Carroli G, Villar J, Piaggio G, Khan-Neelofur D, Gu Imezoglu M, Mugford M, et al. WHO systematic review of randomised controlled trials of routine antenatal care. Lancet 2001; 357(9268):1565-1570. https://doi.org/10.1016/ S0140-6736(00)04723-1.

16. Linard M, Blondel B, Estellat C, Deneux-Tharaux C, Luton D, Oury J, et al. Association between inadequate antenatal care utilisation and severe perinatal and maternal morbidity: an analysis in the pre CARE cohort. BJOG Int J Obstet Gynaecol. 2018;125(5):587-95. https://doi.org/10.1111/1471-052 8.14794.

17. Arunda M, Emmelin A, Asamoah BO. Effectiveness of antenatal care services in reducing neonatal mortality in Kenya: analysis of national survey data. Global Health Action. 2017;10(1):1328796. https://doi.org/10.1080/1654971 6.2017.1328796.

18. WHO. Antenatal coverage. Available at https://www.who.int/whosis/whosta t2006AntenatalCareCoverage.pdf. Accessed 29 Apr 2020.

19. MDG Report. Assessing progress in Africa toward the Millennium Development Goals. Denmark: African Development Bank, Economic Commission for Africa, African Union, United Nations Development Programme; 2011. http://www.undp.org/content/dam/undp/library/MDG/ english/MDG\%20Regional\%20Reports/ADFB-MDG-EN_WEB_final.pdf.

20. World Health Organization. World health statistics 2015: indicator compendium. Geneva: World Health Organization; 2015. https://doi.org/10.1 596/978-1-4648-0440-3.

21. World Health Organization (WHO). Every newborn: an action plan to end preventable deaths. Geneva: WHO; 2014.

22. Shibre G, Mekonnen W. Socio-economic inequalities in ANC attendance among mothers who gave birth in the past 12 months in Debre Brehan town and surrounding rural areas, North East Ethiopia: a community-based survey. Reprod Health. 2019;16(1):99. https://doi.org/10.1186/s12978-0190768-8.

23. Arthur E. Wealth and antenatal care use: implications for maternal health care utilization in Ghana. Heal Econ Rev. 2012;2(1):14. https://doi.org/10.11 86/2191-1991-2-14.

24. Mezmur M, Navaneetham K, Letamo G, Bariagaber H. Socioeconomic inequalities in the uptake of maternal healthcare services in Ethiopia. BMC Health Serv Res. 2017;17(1):367. https://doi.org/10.1186/s12913-017-2298-9.

25. Gebre E, Worku A, Bukola F. Inequities in maternal health services utilization in Ethiopia 2000-2016: magnitude, trends, and determinants. Reprod Health. 2018;15(1):119. https://doi.org/10.1186/s12978-018-0556-x.

26. Goli S, Nawal D, Rammohan A, Sekher TV, Singh D. Decomposing the socioeconomic inequality in utilization of maternal health care services in selected countries of South ASIA and sub-Saharan AFRICA. J Bio Sci. 2017; 50(6):1-21. https://doi.org/10.1017/S0021932017000530.

27. Alam N, Hajizadeh M, Dumont A, Fournier P. Inequalities in maternal health care utilization in sub-Saharan African countries: a multiyear and multicounty analysis. PLoS One. 2015;10(4):e0120922. https:/doi.org/10.1371/journal.pone.0120922.

28. Yaya S, Uthman OA, Amouzou A, Ekholuenetale M, Bishwajit G. Inequalities in maternal health care utilization in Benin: a population based crosssectional study. BMC Pregnancy Childbirth. 2018;18(1):194. https://doi.org/1 0.1186/s12884-018-1846-6.

29. Vallières F, Cassidy EL, McAuliffe E, Isselmou SO, Hamahoullah MS, Lang J. Where are the gaps in improving maternal and child health in Mauritania? The case for contextualized interventions: a cross sectional study. Pan African Med J. 2013;14:97. https://doi.org/10.11604/pamj.2013.14.97.2292.

30. UNICEF Data. Maternal and Newborm Health Disparities - Mauritania [Internet]. UNICEF; 2018 [cited 2021 Sep 29]. Available from: https://data. unicef.org/resources/maternal-newborn-health-disparities-country-profiles/.

31. World Health Organization (WHO). Progress report - reproductive health strategy. To accelerate progress towards the attainment of international development goals and targets. Geneva: World Health Organization; 2010. Available at http://www.who.int/reproductivehealth/publications/general/ rhr_10_14/en/. Accessed 29 Apr 2020.

32. United Nation (UN). The Millennium Development Goals report 2014. New York: United Nations; 2014. Available at http://www.un.org/millenniumgoa Is/2014\%20MDG\%20report/MDG\%202014\%20English\%20web.pdf. Accessed 29 Apr 2020 and within countries.

33. Global Health Observatory $(\mathrm{GHO})$ data. Health Equity Monitor [online database]. Geneva: World Health Organization; 2013. Available at www.who. 
int/gho/health_equity/en/http://www.who.int/gho/health_equity/en/. Accessed 29 Apr 2020.

34. World Health Organization (WHO). State of inequality: Reproductive, maternal, newborn and child health. [Internet]. Switzerland: WHO; 2015. (Interactive Visualization of Health Data). Available from: https:/www-whoint.proxy.bib.uottawa.ca/docs/default-source/gho-documents/health-equity/ state-of-inequality/state-of-inequality-reproductive-maternal-new-born-andchild-health.

35. Hosseinpoor AR, Nambiar D, Schlotheuber A, Reidpath D, Ross Z. Health equity assessment toolkit (HEAT): software for exploring and comparing health inequalities in countries. BMC Med Res Methodol. 2016;16(1):141. https://doi.org/10.1186/s12874-016-0229-9.

36. United Nations Children's Fund (UNICEF). Available at http://ghdx.healthda ta.org/series/multiple-indicator-cluster-survey-mics. Accessed 03 May 2020.

37. Global Health Data Exchange (GHDE). Mauritania Multiple Indicator Cluster Survey 2011. Available at http://ghdx.healthdata.org/record/mauritaniamultiple-indicator-cluster-survey-2011. Accessed 03 May 2020.

38. Global Health Data Exchange (GHDE). Mauritania Multiple Indicator Cluster Survey 2015. Available at http://ghdx.healthdata.org/record/mauritaniamultiple-indicator-cluster-survey-2015. Accessed 03 May 2020.

39. Abekah-Nkrumah $\mathrm{G}$. Trends in utilization and inequality in the use of reproductive health services in sub-Saharan Africa. BMC Public Health. 2019; 19(1):1541. https://doi.org/10.1186/s12889-019-7865-z.

40. World Health Organization (WHO). WHO recommendations on antenatal care for a positive pregnancy experience. Geneva: World Health Organization; 2016.

41. World Health Organization (WHO). Mother-baby package: implementing safe motherhood in countries: practical guide. Geneva: Maternal Health and Safe Motherhood Programme Division of Family, Health World Health OrganisationWorld Health Organization; 1996.

42. Rutstein S, Johnson K. DHS comparative reports no. 6: the DHS wealth index. Calverton: ORC Macro; 2004

43. World Health Organization. Handbook on health inequality monitoring with a special focus on low and middle income countries. Geneva: World Health Organization; 2013. [cited 2019 May18]. Available from: http://www.who.int/ gho/health_equity/handbook/en/.

44. World Health Organization. Health Equity Assessment Toolkit (HEAT): Software for exploring and comparing health inequalities in countries. Builtin database edition. Version 3.1. Geneva: World Health Organization; 2019.

45. Tekelab T, Chojenta C, Smith R, Loxton D. Factors affecting utilization of antenatal care in Ethiopia: a systematic review and meta-analysis. PLoS One. 2019;14(4):e0214848. https://doi.org/10.1371/journal.pone.0214848.

46. Yaya S, Bishwajit G, Ekholuenetale M, Shah V, Kadio B, Udenigwe O. Timing and adequate attendance of antenatal care visits among women in Ethiopia. PLoS One. 2017;12(9):e0184934. https://doi.org/10.1371/journal. pone.0184934

47. Okedo-Alex IN, Akamike IC, Ezeanosike OB, Uneke CJ. Determinants of antenatal care utilisation in sub-Saharan Africa: a systematic review. BMJ Open. 2019;9(10):e031890. https://doi.org/10.1136/bmjopen-2019-031890.

48. Tsala Dimbuene Z, Amo-Adjei J, Amugsi D, Mumah J, Izugbara CO, Beguy D. Women's Education and Utilization of Maternal Health Services in Africa: A Multi-Country and Socioeconomic Status Analysis. J Biosoc Sci. 2017:1-24. https://doi.org/10.1017/S0021932017000505.

49. Kawungezi PC, Akiibua D, Aleni C, Chitayi M, Niwaha A, Kazibwe A, et al. Attendance and utilization of antenatal care (ANC) services: multi-center study in upcountry areas of Uganda. Open J Prev Med. 2015;05(03):132-42. https://doi.org/10.4236/ojpm.2015.53016.

50. WHO. Health workforce requirements for universal health coverage and the Sustainable Development Goals: WHO. [cited 2020 Jan 14]. Available from: http://www.who.int/hrh/resources/health-observer17/en/.

51. Ayanore MA, Pavlova M, Groot W. Unmet reproductive health needs among women in some west African countries: a systematic review of outcome measures and determinants. Reprod Health. 2015;13(1):5. https://doi.org/1 0.1186/s12978-015-0104-X.

52. Peters DH, Garg A, Bloom G, Walker DG, Brieger WR, Rahman MH. Poverty and access to health care in developing countries. Ann N Y Acad Sci. 2008; 1136(1):161-71. https://doi.org/10.1196/annals.1425.011.

53. World bank. Poverty and Health. [Internet]. Available from: Poverty and Health (worldbank.org). Accessed 15 July 2021.

54. Kalu-Umeh NN, Sambo MN, Idris SH, Kurfi AM. Costs and patterns of financing maternal health care services in rural communities in northern
Nigeria: evidence for designing national fee exemption policy. Int J MCH AIDS. 2013;2(1):163-72. https://doi.org/10.21106/ijma.21.

55. Dalinjong PA, Wang AY, Homer CSE. Has the free maternal health policy eliminated out of pocket payments for maternal health services? Views of women, health providers and insurance managers in northern Ghana. PLoS One. 2018;13(2):e0184830. https://doi.org/10.1371/journal.pone.0184830.

56. Philibert A, Ravit M, Ridde V, Dossa I, Bonnet E, Bedecarrats F, et al. Maternal and neonatal health impact of obstetrical risk insurance scheme in Mauritania: a quasi experimental before-and-after study. Health Policy Plan. 2017;32(3):405-17. [cited 2020 Dec 9] Available from. https://doi.org/10.1 093/heapol/czw142

57. Ravit M, Ravalihasy A, Audibert M, Ridde V, Bonnet E, Raffalli B, et al. The impact of the obstetrical risk insurance scheme in Mauritania on maternal healthcare utilization: a propensity score matching analysis. Health Policy Plan. 2020;35(4):388-98. [cited 2020 Dec 9] Available from. https://doi.org/1 0.1093/heapol/czz150.

58. Osamor PE, Grady C. Women's autonomy in health care decision-making in developing countries: a synthesis of the literature. Int J Womens Health. 2016;8:191-202. https://doi.org/10.2147/JJWH.S105483.

59. Grown C, Gupta GR, Pande R. Taking action to improve womens health through gender equality and women's empowerment. Lancet. 2005;365: $541-3$.

60. Nwosu CO, Ataguba JE. Socioeconomic inequalities in maternal health service utilisation: a case of antenatal care in Nigeria using a decomposition approach. BMC Public Health. 2019;19(1):1493. https://doi.org/10.1186/s12 889-019-7840-8.

61. Gupta S, Yamada G, Mpembeni R, Frumence G, Callaghan-Koru JA, Stevenson R, et al. Factors Associated with Four or More Antenatal Care Visits and Its Decline among Pregnant Women in Tanzania between 1999 and 2010. PLoS ONE. 2014;9(7):e101893.

62. Garedew GW, Lemma G, Zegeye B. Knowledge of obstetric danger signs and its associated factors among pregnant women in Angolela Tera District, Northern Ethiopia. BMC Res Notes. 2019;12(1):606. https://doi.org/10.1186/ s13104-019-4639-8.

63. Pandey A, Roy N, Sahu D, Acharya R. Maternal health care services: observations from Chhattisgarh, Jharkhand and Uttaranchal. Econ Polit Wkly. 2004;39(7):713-20.

64. Laksono AD, Rukmini R, Wulandari RD. Regional disparities in antenatal care utilization in Indonesia. PLoS ONE. 2020;15(2):e0224006. https://doi.org/10.13 71/journal.pone.0224006.

65. Soewondo $\mathrm{P}$, Johar M, Pujisubekti R, Halimah $\mathrm{H}$, Irawati DO. Inspecting Primary Healthcare Centers in Remote Areas: Facilities, Activities, and Finances. J Adm Kesehat Indones. 2019;7:89-98. https://doi.org/10.20473/ja ki.v7i1.2019.89-98.

66. Corinne E, Armstrong CE, Martínez-Álvarez M, Singh NS, John T, AfnanHolmes $\mathrm{H}$, et al. Subnational variation for care at birth in Tanzania: is this explained by place, people, money or drugs? BMC Public Health. 2016; 16(Suppl 2):795. https://doi.org/10.1186/s12889016-3404-3.

67. United Nations (UN). Goal 3: Good Health and Well-Being - SDG Tracker. Our World in Data. 2021 [cited 2021 Aug 5]. Available from: https://sdg-tra cker.org/good-health.

\section{Publisher's Note}

Springer Nature remains neutral with regard to jurisdictional claims in published maps and institutional affiliations.

Ready to submit your research? Choose BMC and benefit from:

- fast, convenient online submission

- thorough peer review by experienced researchers in your field

- rapid publication on acceptance

- support for research data, including large and complex data types

- gold Open Access which fosters wider collaboration and increased citations

- maximum visibility for your research: over $100 \mathrm{M}$ website views per year

At $\mathrm{BMC}$, research is always in progress.

Learn more biomedcentral.com/submission 